\title{
Correction to: Potentially toxic elements and polycyclic aromatic hydrocarbons in street dust of Yazd, a central capital city in Iran: contamination level, source identification, and ecological-health risk assessment
}

\author{
Mohammad Javad Nematollahi $(\mathbb{D}$ - Sara Dehdaran - Farid Moore (iD • \\ Behnam Keshavarzi $(\mathbb{D}$
}

Published online: 9 November 2020

(C) Springer Nature B.V. 2020

\section{Correction to:}

\section{Environ Geochem Health}

https://doi.org/10.1007/s10653-020-00682-4

In the original publication of the article, the footnote of Table 6 was incorrectly inserted for Table 5 .
The original article has been corrected.

Publisher's Note Springer Nature remains neutral with regard to jurisdictional claims in published maps and institutional affiliations.

The original article can be found online at https:// doi.org/10.1007/s10653-020-00682-4.

M. J. Nematollahi · S. Dehdaran · F. Moore ( $₫)$.

B. Keshavarzi

Department of Earth Sciences, College of Sciences, Shiraz

University, Shiraz, Iran

e-mail: moore@shirazu.ac.ir

M. J. Nematollahi

e-mail: mjnematollahi.shirazu@gmail.com

S. Dehdaran

e-mail: sara.dehdarann@gmail.com

B. Keshavarzi

e-mail: bkeshavarzi@shirazu.ac.ir 